\title{
To understand and analyze an organization's culture: Theoretical and methodological choices in two decades of research in Brazil
}

\author{
Compreender e analisar a cultura de uma organização: \\ escolhas teórico-metodológicas em duas \\ décadas de pesquisa no Brasil
}

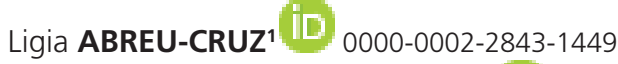 \\ Jairo Eduardo BORGES-ANDRADE ${ }^{1}$ ID 0000-0002-2373-9057

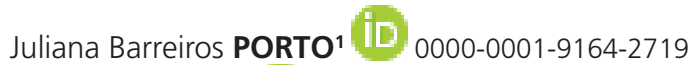 \\ Luiz VICTORINO1 ID 0000-0002-3095-0598
}

\begin{abstract}
Despite the popularity of the organizational culture construct in the organizational psychology's practice, it is important to scrutinize the theoretical and methodological quality standards of its principles in Brazil. The present study investigated 27 articles targeting at an organization's culture, in 18 psychology and administration top-ranked journals, issued between 1996 and 2017. The articles were classified by their theoretical and methodological characteristics, such as type of data analysis, culture definitions, among others, to be further quantified and qualitatively reviewed. The trends were discussed in face of organizational culture's global literature standards, and according to the characteristics of national organizational behavior literature. Special attention was recommended to the alignment between method and epistemology, as well as to a convergence towards global literature's new developments.
\end{abstract}

Keywords: Culture; Research methods, psychology; Organizational psychology.

\section{Resumo}

Apesar da popularidade do constructo "cultura organizacional" na prática do psicólogo organizacional, é preciso questionar a qualidade teórico-metodológica de seus fundamentos no Brasil. Este estudo levantou 27 pesquisas cujo objeto foi a

\footnotetext{
$\checkmark \nabla v$

1 Universidade de Brasília, Instituto de Psicologia, Programa de Pós-Graduação em Psicologia Social, do Trabalho e das Organizações. Departamento de Psicologia Social e do Trabalho. Campus Universitário Darcy Ribeiro, Sala AT-013, Instituto de Psicologia, ICC Sul, 70910-900, Brasília, DF, Brasil. Correspondência para/Correspondence to: L. ABREU-CRUZ. E-mail: <ligiaabreugc@gmail.com>.

Support: Coordenação de Aperfeiçoamento de Pessoal de Nível Superior (Process n 88882.182416/2018-01) and Conselho Nacional de Desenvolvimento Científico e Tecnológico (Process n 403609/2016-0, 303876/2018-2).
}

$\boldsymbol{\nabla} \boldsymbol{\nabla} \boldsymbol{\nabla}$

Como citar este artigo/How to cite this article

Abreu-Cruz, L., Borges-Andrade, J. E., Porto, J. B., \& Victorino, L. (2019). To understand and analyze an organization's culture: Theoretical and methodological choices in two decades of research in Brazil. Estudos de Psicologia (Campinas), 36, e180103. http:// dx.doi.org/10.1590/1982-0275201936e180103 
cultura de uma organização, nos 18 periódicos de psicologia e administração mais bem avaliados no período de 1996 a 2017. Os artigos foram classificados por suas características teóricas e metodológicas, tais como tipo de análise de dados e definições de cultura, dentre outros aspectos, para então serem quantificados e analisados qualitativamente. As tendências foram discutidas frente aos padrões da literatura global sobre cultura organizacional, à luz das características da produção nacional em comportamento organizacional. Recomendou-se especial atenção ao alinhamento entre método e epistemologia, além de aproximação dos avanços da literatura global na área.

Palavras-chave: Cultura; Métodos de pesquisa, psicologia; Psicologia organizacional.

In the early 1980s, the study of culture in humanities was transposed to practice and research in organizations. As a result, the idea that the organizational culture could be a predictor of organizational effectiveness and that its management would be the solution to many problems became popular in business consulting (Chatman \& O'Reilly, 2016). This approach characterizes to date an important part of personnel management. In the academic field a construct has been developed since then: the organizational culture. It is generally defined as the set of assumptions, values, and beliefs shared in an organization. Organizational culture represents the social context of the organization, the "right" way of thinking, feeling and acting in that context and functions as a form of collective identity and commitment (Schneider, Ehrhart, \& Macey, 2013).

Since then, the demand for diagnosis, fostering and change of organizational culture has grown. Organizational diagnosis is the second activity most practiced by organizational psychologists in Brazil and includes the diagnosis of organizational culture (Bastos \& Gondim, 2010). However, one of the main problems affecting the quality of this practice is the inadequacy of theoretical and methodological training. Those who work in organizations in Brazil are often still far from scientific development and methods, which should be the basis for their performance (Bastos \& Gondim, 2010). However, for a grounded practice to occur, scientific literature itself must have theoretical-methodological quality. Systematic reviews assist in this analysis of national production adequacy. In Brazil, the most comprehensive review of organizational culture analyzed articles published until 2001 (Coelho Jr \& Borges-Andrade, 2004) and the most recent review approached only public organizations (Silva \& Fadul, 2010). Updating and broadening of the review focus are required. Thus, the objective of this study was to conduct a systematic review to characterize the theoretical and methodological trends of Brazilian research on organizational culture, when the target is an organization. The literature on organizational culture has been reviewed in order to identify the aspects that should guide the analysis of national publication. Then, a systematic literature review was carried out, which enabled the discussion of the development of this area in Brazil and its future perspectives.

\section{Theoretical-methodological diversity in the field of organizational culture}

The global production on organizational culture is known for the richness of its theoretical and methodological aspects. They resulted into two trends that adopt a frequent opposition between the qualitative and quantitative research approaches (Smircich, 1983). The organizational culture concept arose initially linked to the anthropological qualitative approaches of case studies, analogous to the investigation of rituals and tribes (Schneider, González-Romá, Ostroff, \& West, 2017). This is how Pettigrew (1979) first used the term organizational culture, presenting an approach contrary to the quantitative studies of business administration (Ehrhart, Schneider, \& Macey, 2014). However, since the late 1990s, specific measures and surveys started to be developed for cross-cultural comparative studies. This quantitative trend became stronger and more complex nowadays (Schneider et al., 2017). The coexistence of these two approaches in the study of organizational culture can be better understood by reviewing, in the studies in this area, the following aspects: (a) definitions of organizational culture; (b) objectives; (c) methods used in each approach; (d) culture elements used in the analysis; (e) consideration of the origin and strength of culture, and (f) topics

2 in organizational culture studies. 
Organizational culture is a construct that had multiple definitions. Already at the beginning of its popularization, a classification of the different perspectives was proposed by Smircich (1983), who outlined two investigation agendas: one that described culture as a variable to be studied, "something the organization has" versus approaches that defined culture as a metaphor that explains the organization as a whole, "something that the organization is". The view that organizations are cultures implies studying the patterns of symbolic relations between people, on the basis of the principles of understanding and description. When culture is something that the organization has, culture is represented by variables such as norms, values and beliefs, Smircich explains. Culture is a system that seeks adaptability between its internal components and its environment. Therefore, the big issue would be to analyze how culture can be efficient.

In turn, the different concepts of culture define different methods of study and intervention, since those concepts relate to two opposing assumptions: that each culture is distinct, unique, and that all cultures have universal elements. The first approach, by emphasizing uniqueness, opts for qualitative methods based on inductive and descriptive research (Chatman \& O'Reilly, 2016). On the other hand, the second approach, prefers quantitative methods that favor the principle of comparison, by focusing on universal elements (Ehrhart et al., 2014). Through deductive methods that require hypothesis testing, it is possible to differentiate why one organization is more successful than another.

Interpretative methods seek in-depth analyses of the uniqueness of organizational culture. This stance is related to an emic view, in which a culture can only be described from the meanings attributed by the subjects belonging to that culture. Primarily, these meanings are understood through ethno-methodological, qualitative perspectives. On the other hand, in the approach that seeks to describe universal cultural elements that can be compared across different organizations (etic view), the investigator should use standardized measurement instruments (Chatman \& O'Reilly, 2016). In the first case, generalization goes against the objective of portraying the singularity. In the second case, the goal is to recognize universal patterns in a short period of time, which in turn requires causal investigations. Therefore, the second perspective depends on principles such as prediction, generalization, causality, and control, as Smircich emphasizes (1983).

Thus, one way to understand the different methods is also to identify which culture elements will represent culture in a study. In an approach that has become classic, organizational culture crosses three levels: artifacts (physical environment, organizational practices and policies), adopted assumptions (norms and patterns of behavior), and basic assumptions (shared unconscious truths) (Schein, 2017). Each researcher ought to define if the multiplicity of levels will be studied as a whole or if specific elements will be examined. In the first option, a generalist approach, the inclusion of different cultural manifestations occurs. In the second case, the focus is in a particular culture manifestation, usually elements of more superficial levels (artifacts) (Ehrhart et al., 2014).

In addition to investigating a manifestation of organizational culture, it is necessary to study its source and strength, following the trend of multilevel studies in Organizational Behavior. Organizational levels (micro, meso and macro) are known to be interdependent. Even when the aim of a study is the expression of a phenomenon at one level, its origin can still be located at another level of analysis. Subcultures (meso) and cultures (macro) arise from the congregation and transformation of attributes at the individual (micro) level, such as perceptions, norms, values and assumptions, which become shared (Puente-Palacios, Porto, \& Martins, 2016). Thus, organizational culture has its origin in the emergent process, where lower-level attributes give rise to aggregate-level phenomena. By changing the level, the same phenomenon can change its structure. It is not identical to the level from which it originated. At the same time, after aggregation, the phenomenon continues to be influenced by the individual level. The dynamics of emergence eventually require the researcher to determine if sharing is intense or if there is dispersion in the phenomenon. However, reporting on the strength of culture has been neglected in research reports (Puente-Palacios et al., 2016). 
The notion of culture strength is also supported in personnel management practices. When employees intensely share their views on organizational culture, there are similar expectations as to how they will behave in the organization. This results in less response variability. However, this ideally strong organizational culture has not been the standard format. The reference to a unique culture was already criticized in the 1980s, when it was argued that subcultures exist in the organizations (Schneider et al., 2017; Smircich, 1983). As a result, currently, some researchers are adopting meso levels of analysis in culture studies (Fine \& Hallett, 2014), or even multilevel studies, which include departmental or work unit levels to analyze culture (Huhtala, Tolvanen, Mauno, \& Feldt, 2015).

These and other elements of theoretical-methodological diversity in organizational culture studies are the core aspect that practitioners should know in order to support a practice that lives up to what global research has to offer. At the same time, these professionals should be able to apply and reconstruct global knowledge in the face of local characteristics. Contextual characteristics have been continuously reinforced as being influential in organizational culture (Schneider et al., 2013; Smircich, 1983). To fulfill this task, the professional may have the support of the Brazilian studies on organizational culture.

\section{Theoretical and methodological diversity in Brazilian studies}

Although theoretical-methodological plurality is present in Brazilian scientific production, the description of this reality is scarce. Two articles lend themselves to presenting the epistemological, theoretical and methodological perspectives of the area, when the subject began to generate greater interest among researchers (Ferreira \& Assmar, 1999). However, after the publication of the initial studies, only a few initiatives reviewed and systematized the knowledge development in this country, through psychology and administration journals. The first review covered the period between 1997 and 2007, addressing only research in public organizations (Silva \& Fadul, 2010). Another systematic literature review of these journals was conducted by Coelho Jr. and Borges-Andrade (2004). It included research papers published since 1996, focusing on micro and meso organizational behavior in all types of organizations.

The latter review used a database maintained by three national psychology post-graduate programs. This database serves as an "observatory" for students and teachers of these programs. It has been used as the initial source for systematizing bibliographic information for more than a dozen published systematic literature reviews on specific Organizational Behavior subjects. The journals included in that database are associated to psychology or business, depending on their filiation to a postgraduate course or scientific or professional associations. They are classified as B1, A2 or A1, in Qualis Capes. However, the articles included in the review were published predominantly in the last century (1996-2001), and focused on culture perception, thus excluding topics such as beliefs, values, rites/practices and symbols. There is a need to update that systematic review and further expand the topics associated with the organizational culture (Robinson \& Lowe, 2015).

Both previous reviews did not address the theme taking as analysis criteria the topics mentioned before, at the theoretical-methodological review section, regarding organizational culture global literature. They also did not intended to oppose the Brazilian reality to international production. Finally, no reviews were conducted with a clear intention of improving practice among organizational psychologists. Assuming that these professionals are required to carry out diagnoses and interventions, it should be noted that, in such cases, the object of the study is only an organization (as opposed to investigations that use sampling from different organizations to draw generalist knowledge). Therefore, the aim of the present review was to characterize the theoretical and methodological trends of the Brazilian research on organizational culture, when the target is a specific organization. Subsequently, the intention was to contextualize this production based on Brazilian research in Organizational Behavior, and compare it to the trends in the global study of organizational culture and Work and Organizational Psychology (WOP). 


\section{Method}

Descriptive analyses of the Brazilian scientific literature on organizational culture were performed, when the object of the study was a single organization, through a secondary source of data: the database on national scientific literature in Organizational Behavior, used by Coelho Jr. and Borges-Andrade (2004), described by Borges-Andrade and Pagotto (2010) and later updated until 2017, with the collaboration of post-graduate students trained in systematic literature review. These students, in pairs, year by year, supervised by faculty from the three post-graduate programs already mentioned, searched all the articles that were published in the previously mentioned journals. They selected empirical reports that focused on some Organizational Behavior category or sub-category (descriptors), which are predefined and should be criterion variables (effect, consequence or response associated with a supposedly antecedent or independent variable). Another pair of students, equally supervised by faculty, reviewed this selection (deleting or reclassifying incorrectly identified articles). If the published articles surveied by the first pair were confirmed, the second pair would read these reports, paying special attention to the described criterion variables, methods and results sections. Then, they would identify and classify any criterion variables found. Finally, in successive columns of an excel spreadsheet, this pair recorded standardized information regarding authors and their institutions, procedures and instruments for data collection and analysis (quantitative or qualitative) and sample characteristics (alleged beneficiaries of the investigation). In this database, articles containing only reports of empirical investigations, which data were collected in Brazil, were selected and classified in those predefined Organizational Behavior categories, between the years 1996 and 2017 - in 18 national journals of psychology and business. New journals have been included in that database since its set up and previous description by Borges-Andrade and Pagotto (2010): Revista de Administração Mackenzie, Revista Eletrônica de Administração, Paidéia USP-Ribeirão Preto, Brazilian Administration Review and Avaliação Psicológica. Among those categories (descriptors), there is one for organizational culture, designed to group articles whose criterion variable refers to the sub-categories (descriptor's subdivisions of "organizational culture"): beliefs; values; rites or practices; symbols; culture perception. As a criterion for selecting articles in this category, only studies conducted in a single organization were considered. This selection resulted in 27 articles approaching the subject in question².

The other standardized information that make up the database allowed organizing the pre-existing data into two subsets. A first grouping of data described the national context that supports the production on the matter: the number of articles and their growth trend (based on the year of publication); the territorial region and the knowledge area of the authors (based on institutional affiliation and last obtained educational title); the journals that published the papers; the economy sector and the economy segment studied (based on the sample description). A second set of data, pertinent to the main objective of this article, described the most used methodological choices in the area: (a) nature of the study; (b) research design; (c) nature of the research (qualitative, quantitative or quali-quantitative/mixed); (d) data source; (e) instruments used; and (f) data analysis procedure. These two datasets, therefore, had been included in the aforementioned spreadsheet, following the procedures previously described (pairs of "referees", post-graduate students, supervised by faculty).

In a third step, the articles were reviewed by this manuscript author(s) in order to raise aspects not covered by the categories of the pre-existing database. In order to fulfill this function, new categories were deductively defined by the authors. The purpose was to represent the core aspects of international literature

$\operatorname{rrv}$

2 These articles are not cited here, as this would entail the need to include 27 more references, which would result in a substantial increase in the number of pages in the journal, and would not meet the $50 \%$ requirement for updated references. 
on organizational culture, as described in the introduction of this study: (a) definition of the organizational culture construct; (b) epistemological perspective on the subject (through the assessment of the theories presented); (c) elements chosen to describe the culture; (d) presence/absence of considerations about the data source and culture strength. In order to further detail the statistical analyses reported in those papers, the analyses should be classified as exploratory, test of relationship between variables or model testing. Moreover, the number of studies that used univariate or multivariate statistics were calculated. Finally, the antecedent/independent variables in relation to the organizational culture were also addressed.

The first data set, which describes the context of literature production on the subject organizational culture (in a given organization), was compared to the context of the overall national Organizational Behavior production (based on the information available in the aforementioned database), using the same methodological procedure. The information that refers to the method in organizational culture studies could also be compared to the method in Organizational Behavior in general using this database. The results are presented in a comparative format, leaving aside data that, when crossed, did not produce relevant comparisons. Finally, all methodological characteristics were reviewed in relation to the field of study of the organizational culture within a global scope.

\section{Results}

\section{The national context of organizational culture research}

In the period reviewed, from 1996 to 2017, a total of 1,062 organizational behavior papers were published in Brazil. However, only 27 focused on organizational culture, investigated in a single organization. This scientific production is still relatively small. Publications maintain a relatively stable trend over time: at least 2 articles were published yearly during the periods 1999-2003 and 2013-2015. In the other years, production varied (minimum one, maximum three articles). In addition to the low absolute amount of publication, a mismatch may be observed between the clear upward trend of studies in overall Brazilian Organizational Behavior publication and that on culture in an organization, which has remained small and stable over the years.

The results point at publications by authors from regions where scientific production of Organizational Behavior has been traditionally stronger in Brazil. The institutions of the first authors of the articles were located only in the South, Southeast and Midwest, except for one paper from Bahia (Northeast). The Southeast region concentrates most of the authors (48.2\%), almost the same number of the other two regions (South and Central West, 44.4\%).

The studies were published in the following journals: Organizações \& Sociedade, Revista de Administração Mackenzie, Revista de Administração Pública (4 articles each); Revista de Administração Contemporânea (3 articles); Revista Eletrônica de Administração, Revista de Administração da USP, Revista de Administração de Empresas (2 articles each); Estudos de Psicologia (Natal), Estudos de Psicologia (PUC Campinas), Psico USF, Psicologia, Ciência e Profissão, Paidéia and Revista Psicologia Organizações e Trabalho (1 article each). Therefore, the journals that published most articles on the subject belong to the business area. The psychology journals have published, each one, only one article during the studied period. In the case of Organizational Behavior publications in general, a more balanced distribution is observed, with $50 \%$ of the articles being published in business journals, as well as a higher concentration of articles published in rPOT. Accordingly, most of the authors were associated with the business area: a total of 21 first authors, compared to only six in psychology. In contrast, the authors of the Organizational Behavior publications, in general, have a more well-distributed affiliation between psychology and business (47.2\% and $37.8 \%$, respectively). 
In the subset of papers on culture in an organization, $91.7 \%$ of the cases used the tertiary sector as a sample, and this sample showed a balance between public (54.2\%) and private $(45.8 \%)$ organizations. Publications based on experience reports, without clear research designs, ceased in 2005, yielding to papers with descriptions of research procedures. These data are very similar to those of Organizational Behavior, in general, where the abandonment of publications without a clear methodological design is evident and the tertiary sector is the most investigated. In turn, the balance between sectors is even greater: $43.2 \%$ of studies in public organizations and $41.5 \%$ in private organizations.

\section{Methodological choices}

In Brazilian investigations on Organizational Behavior in general, there was a change from the qualitative method that initially characterized the field, towards quantitative and mixed research methods. Accordingly, the most frequently reported survey instruments are questionnaires or scales (50.2\%) and interviews (29.5\%) for the data collection of primary origin (91.4\%). In $51.2 \%$ of the cases, the samples originated from different organizations (not just from one organization). The analysis of the data also reflects the predominance of a quantitative approach, as $44.3 \%$ of the articles use inferential statistics as their primary analysis. On the other hand, when the sample is restricted to studies of culture in a single organization, the methodological strategies are more related to the qualitative approach, as shown in Table 1. When inferential analyses were used, it was done for the construction of measurement instruments ( $7.4 \%$ of the studies). Therefore, the aim was to develop an instrument, instead of actually analyze an organizational culture.

Table 1

Characteristics of methods in national studies in organization's culture

\begin{tabular}{|c|c|c|}
\hline Characteristics & Frequency $(n)$ & Percentage \\
\hline \multicolumn{3}{|l|}{ Study design } \\
\hline Survey & 26 & 96.3 \\
\hline Action research & 1 & 3.7 \\
\hline \multicolumn{3}{|l|}{ Nature of research } \\
\hline Quantitative & 8 & 29.6 \\
\hline Qualitative & 13 & 48.1 \\
\hline Qualitative-quantitative & 6 & 22.2 \\
\hline \multicolumn{3}{|l|}{ Data origin } \\
\hline Primary & 20 & 74.1 \\
\hline Secondary & 7 & 25.9 \\
\hline \multicolumn{3}{|l|}{ Instruments used } \\
\hline Questionnaries/Scales & 17 & 63.0 \\
\hline Interview & 9 & 33.3 \\
\hline Observation & 1 & 3.7 \\
\hline \multicolumn{3}{|l|}{ Data analysis procedure } \\
\hline Inferential & 7 & 25.9 \\
\hline Descriptive & 10 & 37.0 \\
\hline Content Analysis & 10 & 37.0 \\
\hline
\end{tabular}




\section{Comparison with global scientific literature: Elements and dynamics in the definition of culture}

In several papers, there were no sections clearly defining an organizational culture concept. This resulted in the need to search, throughout the text, for elements that would clarify how this concept was defined by the authors of the articles. Such elements may be grouped into two different conceptions: on the one hand, there were articles that emphasized the cognitive aspect of culture, with constructs such as attitudes, beliefs, thoughts and, seldom, perception. Only one article referred to the affective aspect of organizational culture. On the other hand, aspects of the social context were highlighted, such as cultural norms, rules and standards. In this second trend, the organization was presented as a builder of social relations, through terms such as symbols, rites, myths, communication, policies, among others. Only this perspective referred to behavior as part of the organizational culture. Still, regardless of the approach, the construct "values" was the most quoted term (in 10 out of 27 articles) and served as reference to the unconscious character of organizational culture (in only one article).

Some resemblance may then, be noted, between the two approaches of the classic division proposed by Smircich (1983): "something that the organization has" versus "something that the organization is". The first portion of data (articles that emphasized the cognitive aspect of culture) may be associated to the first approach, through conceptions in which the social context and the organizational structure represent something that the organization is. However, the definitions in the articles made no mention as to the type of perspective to which they subscribe. Further, they showed no concern in justifying the selection of the elements (values, beliefs, cultural patterns) that structure their notion of culture. Most definitions seemed to include a variety of cultural manifestations, according to the generalist character identified by Ehrhart et al., 2014. However, these same definitions were clearly intended to carry out an in-depth study. Therefore, this does not justify the option to use mostly more superficial elements of the phenomenon (norms, communication, rites) among the manifestations that define organizational culture.

Regarding the dynamics of the concept of organizational culture, 7 out of the 27 articles indicated that culture is a shared construct, in most cases highlighting its character of homogeneity and integration. In fact, only one article mentioned a potential cultural heterogeneity. Out of the total number of articles, 3 highlighted that culture is dynamic, developed in everyday learning. Despite some degree of dynamism and reference to dispersion in some concepts, no article referred to the issue of the culture strength or origin, nor was the context of subcultures mentioned. These and other aspects of the dynamics of culture - degree of sharing or dispersion, origin and strength - were addressed only in the conceptual and theoretical realm, and data treatment for their investigation is absent.

\section{Statistical analyses and culture-related variables}

Out of the 27 articles, 12 reported descriptive analyses of the data. The same number of papers indicated the intent to test the relationship between variables and only 2 presented a relationship model to be investigated. This scenario is consistent with the finding of only 7 articles in which multivariate and not univariate statistics were used. Using these analysis procedures, constructs that represent the organizational culture were explored, organized in typologies or even related to each other. Other constructs, representing variables external to the culture itself, were also investigated, especially with reference to the subject of organizational structure (implementation of information technologies, outsourcing, training evaluation, internal marketing). This subject was reviewed, discussing how social relations are organized: hierarchization, authoritarianism, paternalism, perception of accessibility and interaction between leaders. Other aspects of the organization's functioning were also reviewed, such as formalism, freedom vs. slavery, dependence vs. independence and planning vs. improvisation. 
Another set addresses variables that were theoretically defined as constructs derived from shared perceptions - the perception of efficiency, the perception of institutional prestige and the perception of organizational cynicism - and social representations (treated in general). However, no statistical analyses were performed to verify such sharing. Still, individual aspects were portrayed: proactive and reactive behavior, self-criticism, meanings of work, work values and pleasure-suffering at work. The influence of society outside the organization was approached under the theme internationalization, as well as "the Brazilian way" and relational society.

\section{Discussion}

The largest number of articles on organizational culture was published by the following top four journals: Revista de Administração Contemporânea, Revista de Administração Mackenzie, Organizações \& Sociedade, and Revista de Administração Pública. However, the journal that published most of the articles on Organizational Behavior, the Revista Psicologia Organizações e Trabalho journal of psychology, was not included among them. The "absence" of the first ranking journal and the journals' profile reflect the fact that studies are concentrated in the business area, produced by authors with business degress and in a region where business management is a popular topic (South and Southeast regions). This data is corroborated by a larger number of studies in private organizations, unlike the Organizational Behavior production in general.

Regarding methodological choices, the replacement of studies without research design for those that use surveys, and the predominance of data collection with primary source of data, demonstrates an evolution similar to Organizational Behavior studies in Brazil. It also demonstrates an intention to keep up with the global scenario. In this context, there has been a replacement of the dominant qualitative analysis by surveys that use a quantitative approach (Schneider et al., 2013) and there is an incipient attempt to produce mixed methods research (Gover, Halinski, \& Duxbury, 2016). The option for quantitative analysis in WOP has been accompanied by the use of increasingly advanced statistical treatments, due to the growing interest in relating dimensions of different levels of analysis (Feitosa, Salas, \& Borges-Andrade, 2018). However, in the opposite direction to the development of Organizational Behavior in Brazil, which converges to global studies on WOP and on organizational culture, inferential statistical analyses were scarcely present. Further, those analyses were performed for scale validation studies and simple correlation. Similarly, studies classified under a mixed-method design paradigm offered unreliable procedures. Just like in the global scenario, the use of mixed methods in this field is still a problem. In organizational culture studies, qualitative and quantitative approaches are not just strategies of analysis, but epistemological positions, bounded to competing views of culture, a fact that hinders their integration (Chatman \& O'Reilly, 2016). In national studies, mixed procedures were observed, but without complementarity between both approaches.

This profile of methodological choices could be accounted for the definition of organizational culture. Within the perspective in which organizations "are" cultures, the objective is the description and understanding of the meanings shared by the members of the organization. Thus, the trend is to use the inductive method in a qualitative approach (Schneider et al., 2013). This approach tends to emphasize the unique aspects of cultures through descriptive research (Ehrhart et al., 2014). In contrast, the analysis performed in currrent studies did not seem to point out to choices based on a clear commitment to some epistemological-methodological approach. In fact, there was a lack of theoretical bonds in the definitions of culture. In some articles, the concept of culture was not presented in a specific section of the text. When this occurred, the definitions themselves were mostly inaccurate or vague. In addition, they presented terms committed to different approaches, or even omitted or added constructs to classical literature definitions. 
Epistemological inconsistency continues through the subjects addressed and the definition of objectives. Most of the themes and analysis were in opposition to the qualitative approach, which allegedly characterized the studies. The systemic view, aligned with a more quantitative approach, presumes that it is possible to increase the effectiveness of culture (Smircich, 1983). This view seems to be implicit in the subjects associated with the organizational culture in most articles, which seek better adaptation with structural, contextual, and even individual characteristics. The contradiction between analytic intent and subjects of investigation can also be noted in cases where it was stated that the impact of an event on culture would be demonstrated (change, outsourcing, training). However, the analysis actually performed was only the description of aspects of culture and there was not a test of the relationship between variables.

The results of this review also suggest methodological incoherence in the selection of analytical procedures. An option for content analysis and descriptive statistical analysis could indicate an adjustment to the logics of the inductive approach. However, it was observed that the most commonly used instruments were questionnaires and interviews in closed formats. The strategies that characterize a comprehensive and descriptive approach are mostly the ethnographic tradition methods, according to Chatman and O'Reilly (2016). These were not actually used in the articles. It can be assumed that, when defining procedures, more common instruments in the literature or more convenient instruments were selected.

Moreover, there was no analysis to verify if the different constructs used in each article (norms, values, behavioral patterns) were actually shared by the participants, although the concept of culture contains in its essence the idea of sharing (Puente-Palacios et al., 2016; Schein, 2017). Whether consistent with the qualitative approach present in most articles, or in the quantitative articles, there were no procedures for testing the degree of culture sharing or the existence of subcultures. At most, the theoretical reference to potential ambiguity and heterogeneity stood out. This neglected aspect demonstrates a mismatch between the advance of global research on culture and Brazilian research.

In summary, it is possible to observe two general characteristics in the national production about the culture of an organization. The first resumes itself in authorship and the target audience in the business area. The second, a tendency to define culture as "something that the organization is" (Smircich, 1983) and the qualitative approach deriving from it. This trend differs from both national Organizational Behavior production and global production on organizational culture. The problematic aspect of this second feature, however, is not the fact that it is getting distant from other scenarios, but the aforementioned inaccuracy in its epistemological-methodological identity. The need to align theory and method is a recurring recommendation found in reviews on organizational culture at global level (Giorgi, Lockwood, \& Glynn, 2015).

It is known that the parameters for publication of qualitative research differ from those for quantitative research. A series of recommendations for the publication of qualitative studies has been issued by the American Psychological Association (APA), emphasizing mainly two major principles that support this type of research: contextualization and transparency (Levitt et al., 2018). Therefore, variations are allowed in the classic format of publication, in which the sections of an article must be easily detached from the text and aim at objectivity. Alternatively, narrative formats are encouraged, in which the rationales for methodological choices are introduced throughout the text, accompanying the presentation of results or even the discussion. However, they should maintain methodological integrity. Authors should make it clear which is the purpose of the study, how it relates to its background and expectations, besides justifying each methodological selection (Levitt et al., 2018). Still about the principle of transparency, authors should contextualize how the investigation topic has been socially conceived, especially for the sample in question.

Among the articles reviewed, the narrative format was present, which often met criteria such as: presenting examples and evidence that support the analyses, justifying the subject and the selection of the method from a theoretical point of view and sometimes a detailed contextualization of the investigation 
site. There was an emphasis on the review of theoretical references and subsequent analysis of the results to seek corresponding matters in the literature. However, almost no reviewed articles offered the necessary contextualization about researchers and participants. The principle of transparency, also, suffered mainly from narratives that, in many cases, indicated only a few steps of the methodological procedures, leaving gaps in the explanation. Still, most of the papers did not include detailed objectives or had unclear objectives that varied along the text.

In turn, the first characteristics of literature production - being restricted within the business boundaries - may partly explain the aforementioned deviation between theory and practice in the activities of psychology professionals. They will find the studies on organizational culture confined within the business area. Therefore, it can be assumed that the studies are still aligned with the logic of business usefulness, which characterizes the first phase of the concept of organizational culture in management practices. These data demonstrate the importance of context consideration in the characterization of trends in Organizational Behavior, since organizational behavior is determined by the work format in a country, due to its history, culture, legal, economic, religious, language issues, among others (Roe, 2018).

In addition, a third characteristic deserves to be mentioned, even if it is not exactly a core feature to describe Brazilian production on the culture of an organization: the presence of research for the development and validation of measuring instruments. Investigations seeking evidence of scales validity converge with current global demand, as only a minor number of measures in this area have acceptable levels of validity and reliability (Denison, Nieminen \& Kotrba, 2014) and serious questions are raised about the existing scales' construct validity (Chatman \& O’Reilly, 2016).

\section{National agenda for organizational culture investigation}

In view of the imprecision of a qualitative trend that characterizes the studies on organizational culture in Brazil, it is necessary, once again, to take into consideration the national context and, at the same time, seek integration with global literature (Feitosa et al., 2018). Theoretical-methodological plurality is typical of Organizational Behavior field, which has always been part of the organizational culture subject, either nationally or globally (Borges-Andrade \& Pagotto, 2010; Porter \& Schneider, 2014). However, a tendency is observed in this field, consisting in resorting to increasingly advanced methods of multilevel quantitative analysis. This does not exclude local peculiarities or even other options of global trends. Further refinement of the qualitative method would already align national production to typically European trends in WOP research. In Europe, there is a tradition of methods that value workers' subjective vision, creativity and meanings creation, so that greater weight is given to the definition of concepts and theorization (Roe, 2018).

An alignment between theory and procedures is still incipient, as observed in the reviewed articles. The aforementioned APA recommendations can assist national researchers in this regard and in the development of a consensus on how to plan and publish qualitative studies in Brazil. Still in connection with this aspect, not only questionnaires and interviews are used, but essays, drawings, games and group discussions (Roe, 2018). The diversity of data collection instruments is in line with the international tradition in organizational culture, which attaches great importance to document analysis and to the different artifacts used for understanding the culture of an organization (Schein, 2017), which assumes the valuation of secondary data. However, the predominance of primary data in the reviewed articles is evident, as well as a seemingly convenient selection of data collection instruments. Finally, it is necessary to adopt more complex analysis in order to encompass its different levels and the force and the origin of the culture. This deficit may be part of the national context: most empirical production in developing countries uses simple methods of analysis (Feitosa et al., 2018). 
More than the theoretical and methodological improvement required by the scientific community, it is necessary to evaluate all literature on Organizational Behavior considering the demands of its beneficiaries. The development of the literature in question has been confined in the field of business. However, organizational psychology has shown to be one of the main areas to absorb psychology professionals (Bastos \& Gondim, 2010) and has demanded a quality of education that is not found in psychology journals. The low scientific production and stagnation in its growth affect the psychologist's appropriation of the matter. Although the global literature on organizational culture is sufficiently rich and complex, articles published in Portuguese, developed by Brazilians, about organizations that operate in this country, still guide the practice of most of its professionals.

\section{Contributors}

L. ABREU-CRUZ Study conception and planning, data analysis and discussion, manuscript writing. J.E. BORGES-ANDRADE guidance on data collection, organization and analysis, multiple revisions of the written text, writing of excerpts. J.B. PORTO text review, literature suggestion, assisted in the discussion of the results. L. VICTORINO data collection and analysis, text review.

\section{References}

Bastos, A. V. B., \& Gondim, S. M. G. (2010). O trabalho do psicólogo no Brasil. Porto Alegre: Bookman.

Borges-Andrade, J. E., \& Pagotto, C. P. (2010). O Estado da arte da pesquisa brasileira em psicologia do trabalho e organizacional. Psicologia: Teoria e Pesquisa, 26(Número Especial), 37-50. http://doi.org/10.1590/S010237722010000500004

Chatman, J. A., \& O'Reilly, C. A. (2016). Paradigm lost: Reinvigorating the study of organizational culture. Research in Organizational Behavior, 36, 199-224. http://dx.doi.org/10.1016/j.riob.2016.11.004

Coelho Jr, F. A., \& Borges-Andrade, J. E. (2004). Percepção de cultura organizacional: uma análise empírica da produção científica brasileira. PsicoUSF, 9(2), 191-199. http://doi.org/10.1590/S1413-8271200400020001

Denison, D., Nieminen, L., \& Kotrba, L. (2014). Diagnosing organizational cultures: A conceptual and empirical review of culture effectiveness surveys. European Journal of Work and Organizational Psychology, 23(1), 145-161.

Ehrhart, M. G., Schneider, B., \& Macey, W. H. (2014). Organizational climate and culture: An introduction to theory, research, and practice. New York: Routledge.

Feitosa, J., Salas, E., \& Borges-Andrade, J. E. (2018). Industrial, work and organizational psychology in Latin America. In N. Anderson, C. Viswesvaran, H. K. Sinangil, \& D. S. Ones (Eds.), The SAGE Handbook of industrial, work, and organizational psychology: Managerial psychology and organizational approaches (pp.149-158). London: SAGE.

Ferreira, M. C., \& Assmar, E. M. L. (1999). Perspectivas epistemológicas, teóricas e metodológicas no estudo da cultura organizacional. Revista Educação \& Tecnologia, (4), 11-21.

Fine, G. A., \& Hallett, T. (2014). Group cultures and the everyday life of organizations: Interaction orders and mesoanalysis. Organization Studies, 35(12), 1773-1792. http://dx.doi.org/10.1177/0170840614546153

Giorgi, S., Lockwood, C., \& Glynn, M. A. (2015). The many faces of culture: Making sense of 30 years of research on culture in organization studies. The Academy of Management Annals, 9(1), 1-54. http://dx.doi.org/10.1080/19416 520.2015 .1007645

Gover, L., Halinski, M., \& Duxbury, L. (2016). Is it just me? Exploring perceptions of organizational culture change. British Journal of Management, 27(3), 567-582. http://dx.doi.org/10.1111/1467-8551.12117

Huhtala, M., Tolvanen, A., Mauno, S., \& Feldt, T. (2015). The associations between ethical organizational culture, burnout, and engagement: A multilevel study. Journal of Business and Psychology, 30(2), 399-414. http://dx.doi.org/10.1007/ s10869-014-9369-2

Levitt, H. M., Bamberg, M., Creswell, J. W., Frost, D. M., Josselson, R., \& Suárez-Orozco, C. (2018). Journal article reporting standards for qualitative primary, qualitative meta-analytic, and mixed methods research in psychology: The APA Publications and Communications Board task force report. American Psychologist, 73(1), 26-46. http://dx.doi. org/10.1037/amp0000151 
Pettigrew, A. M. (1979). On studying organizational cultures. Administrative Science Quarterly, 24(4), 570-581. http:// dx.doi.org/10.2307/2392363

Porter, L. W., \& Schneider, B. (2014). What was, what is, and what may be in OP/OB. Annual Review of Organizational Psychology and Organizational Behavior, 1, 1-21. http://dx.doi.org/10.1146/annurev-orgpsych-031413-091302

Puente-Palacios, K. E., Porto, J. B., \& Martins, M. D. C. F. (2016). A emersão na articulação de níveis em Psicologia Organizacional e do Trabalho. Revista Psicologia Organizações e Trabalho, 16(4), 358-366. http://dx.doi.org/10.17652/ rpot/2016.4.12603

Robinson, P. E., \& Lowe, J. (2015). Literature review vs systematic reviews. Australian and New Zealand Journal of Public Health, 39(2), 103. http://dx.doi.org/10.1111/1753-6405.12393

Roe, R. A. (2018). Industrial, work and organizational psychology in Europe. In N. Anderson, C. Viswesvaran, H. K. Sinangil, \& D. S. Ones (Eds.), The SAGE Handbook of Industrial, Work, and Organizational Psychology: Managerial psychology and organizational approaches (2 ${ }^{\text {nd }}$ ed., pp.46-75). London: SAGE.

Schein, E. H. (2017). Organizational culture and leadership. Hoboken: John Wiley \& Sons.

Schneider, B., Ehrhart, M. G., \& Macey, W. H. (2013). Organizational climate and culture. Annual Review of Psychology, 64, 361-388. http://dx.doi.org/10.1146/annurev-psych-113011-143809

Schneider, B., González-Romá, V., Ostroff, C., \& West, M. A. (2017). Organizational climate and culture: Reflections on the history of the constructs in the Journal of Applied Psychology. Journal of Applied Psychology, 102(3), 468. http:// dx.doi.org/10.1146/annurev-psych-113011-143809

Silva, L. P., \& Fadul, E. (2010). A produção científica sobre cultura organizacional em organizações públicas no período de 1997 a 2007: um convite à reflexão. RAC: Revista de Administração Contemporânea, 14(4), 651-669. http://dx.doi. org/10.1590/S1415-65552010000400006

Smircich, L. (1983). Concepts of culture and organizational analysis. Administrative Science Quarterly, 28(3), 339-358. http://dx.doi.org/10.2307/2392246

Received: September 25, 2018

Final version: June 19, 2019

Approved: September 16, 2019 